\title{
UN RECUERDO INFANTIL DE LEONARDO DA VINCI (1910)
}

\author{
Dr. Fco Javier de Santiago Herrero ${ }^{1}$
}

"He de confesar, ante todo, que soy profano en cuestión de arte. El contenido de una obra de arte me atrae más que sus cualidades formales y técnicas a las que el artista concede, en cambio máxima importancia. Para muchos medios y efectos del arte me falta, en realidad, la comprensión debida y quiero hacerlo constar así para asegurar a mi intento presente una acogida benévola" (O.C.III, 1877). Con estas frases comienza Freud su escrito sobre "El Moisés de Miguel Ángel” de 1913 [1914], y me parecen del todo acertadas trasferirlas a 1910 y más aún a 2007, pues en las palabras que a continuación les voy a presentar en verdad yo no digo nada nuevo, sólo me impongo la labor de tratar de resumir y hasta entender para que ustedes lo entiendan algo de lo ya escrito. Y aquí ya entramos en un conflicto, pues ustedes esperan algo de mí y yo de ustedes. Todo este rodeo, en fin, para decir, que no se a penas de arte, sin embargo algo he estudiado y creo que he comprendido un poco de psicoanálisis.

Una de las cuestiones más fascinantes, quizá que tenga el psicoanálisis es su vertiente aplicada. Es decir, el psicoanálisis extramuros, del que habla Laplanche. Ya Freud en 1914 en Múltiple interés del psicoanálisis nos dice lo siguiente:

“...el psicoanálisis aspira a interesar a hombres de ciencia distintos a los psiquiatras, pues se extiende a otros varios sectores distintos y establece entre ellos y la patología de la vida psíquica relaciones insospechadas" (O.C. II, p. 1851)

Es decir el psicoanálisis ofrece en cuanto "psicología profunda aplicada" la oportunidad de profundizar desde la hermenéutica en todas las ciencias del hombre (biología, literatura, filosofía, arte, psiquiatría, psicología, pedagogía, etc).

Para Gómez Sánchez (2002) el psicoanálisis aplicado debe tener como referentes:

Primero: Una analogía con los procesos patológicos. Lo que es lo mismo que plantear que entre la presunta normalidad y la neurosis no existe discontinuidad sino que son

\footnotetext{
${ }^{1}$ Universidad de Salamanca. Correo electrónico: desantiago@usal.es
} 
procesos de una línea continua y por lo tanto solo identificables en cuanto al grado.

Sería como una caja de música en la que sólo varía el volumen de la melodía.

Segundo: La búsqueda de la génesis. El psicoanálisis aplicado busca regresar al origen de la fuente, al hilo primigenio de la madeja, de esa enorme bola de lana para tras tirar de ella ir redescubriendo todo el proceso de forma atemporal, pues el inconciente se encuentra fuera del tiempo y;

Tercero: Traslucir las funciones psíquicas que operan en el fenómeno observado.

En base a ello, si enlazamos los grandes temas freudianos de la neurosis y los sueños con cualquier fenómeno de la vida, ya sea el arte, ideologías, etc cobran sentido las siguientes palabras del maestro vienés en su obra Tótem y Tabú:

"Las neurosis presentan, por una parte, sorprendentes y profundas analogías con las grandes producciones sociales del arte, la religión y la filosofía, y por otra, se nos muestran como deformaciones de dichas producciones. Podríamos casi decir que una histeria es una caricatura de una obra de arte, que una neurosis obsesiva es una caricatura de la religión y que un delirio paranoico es una caricatura de un sistema filosófico deformado. Tales deformaciones se explican en último análisis por el hecho de que las neurosis son formaciones asociales que intentan realizar con medios particulares lo que la sociedad realiza por medio del esfuerzo colectivo" (O.C.II.p. 1794)

Acerca del tema que nos trae hoy aquí, se puede decir que el estudio de Leonardo constituye el trabajo más amplio que Freud dedica a la interpretación de una personalidad creativa. Sus trabajos anteriores, sobre psicoanálisis aplicado, son más bien breves. En 1904 Personajes psicopáticos en el teatro o en 1908 El poeta y la fantasía. Freud en este caso se enfrenta a la obra del pintor documentado por sus biógrafos (Monedero, 1985) y, si bien se recuesta en una mala traducción de sus pocos escritos, también se apoya en las obras que el dejó a través de sus pinturas.

Pero, antes de entrar en la materia solo unas brevísimas palabras en torno al proceso creativo, pues de ello se ha escrito mucho y bien. Alonso Fernández (1984) sistematiza tal proceso apoyándolo en un trípode de factores:

1.- Un pensamiento lógico-racional, que guía las ideas objetivas y subjetivas. Es decir, más allá del puro reflejo animal si se entiende mejor la exageración. 
2.- El inconsciente y su actividad creadora, pero no sólo el inconsciente que va recogiendo el material reprimido, que también, sino un centro psíquico profundo donde opera la creatividad (preconsciente, yo inconsciente, fronteras del yo...)

3.- Una sólida inteligencia como soporte de todo, entendida como capacidad de síntesis y de selección de lo esencial (ibid p. 117). En este último punto ya habría discusiones teóricas, científicas e incluso desacuerdos dentro del pensamiento cotidiano que pesa tanto como el científico.

No obstante, en el personaje que nos trae hoy aquí se cumplen a la perfección los tres requisitos antes mencionados. Cualquiera que se acerque a la figura de Leonardo lo primero que le llama la atención es su polimatheia, o disposición múltiple para las artes y saberes, técnicos y humanos sin distinción; que aparecen en Leonardo como la única forma lógica en la que sus obras pueden desarrollarse (Ramos, 2005 p. 8-9). Pero esta forma, aparentemente tan lógica y lineal, esconde una trama más compleja si ahondamos en el mundo pulsional del genio. Toda la vida de Leonardo está focalizada por una irresistible compulsión a saber. Podría decirse que inclusive su capacidad artística era un don secundario a esa imperiosa necesidad de saber. Una prueba de ello lo tenemos en su cuadro La Ultima Cena, que tardó diez años en pintar - 1488 a 1498 ${ }^{2}$, al poco de terminarla ya estaba bastante deteriorado pues en el creador prevalecía la idea de introducir nuevas técnicas de pintura en su obra más que la obra en sí. La sublimación de la pulsión en investigación en este caso nos indica sin más que Leonardo prefería descubrir que actuar, mirar que participar, crear mundos que respirar en ellos. El problema es terrible, porque la sublimación se cargó a la persona, y casi al artista, sublima condenado a no satisfacer su sexualidad. Sólo queda una duda razonable, ¿Qué hubiera sido de tanta pulsión si no hubiera tenido Leonardo esa capacidad de sublimar?...

Ahora bien, tan poco podemos pecar de ingenuos, Leonardo satisfacía algo sexual hay donde investigaba y ese algo no podía ser otra cosa que su propio narcisismo, un narcisismo voraz que necesita saber más y más, porque el saber es dominio y el dominar transciende de lo humano. Aquí entraríamos de pleno en todo el tema de la rebelión contra el padre, pero perdonen que no me quiera adelantar. No

\footnotetext{
${ }^{2}$ Ubicada en el Convento de Santa María delle Grazie de Milán sobre el muro que preside el refertorio de los monjes.
} 
obstante, ese instinto de saber le juega una mala pasada en horas de presumible dolor a nuestro artista. El padre muere y en la necrológica escrita por el propio hijo, aviso que no va más allá de dos líneas y media, Leonardo comete dos errores consecutivos. El primero es que señala por dos veces la muerte de su padre "Addi 9 de Luglio 1504, miercoledi, a ore 7, morí Ser Piero da Vinci, notalioo al palazzo del Potestà, mio padre, a ora 7" Y el segundo error, mas grave es que atribuye al padre 80 años cuando en realidad contaba con 77. La hipótesis más plausible es que Leonardo que había abandonado la casa paterna siendo un adolescente pasaba en lo consciente olímpicamente de su padre, pero Freud es extremadamente prudente en este escrito y a falta de datos se limita a subrayar el fenómeno. Digo que pasaba conscientemente de su padre porque inconscientemente estuvo ligado a él toda su vida, mas de lo que suponía, por ello yo pienso que dichos errores encierran más de liberación de lo que puede parecer. Al final no me va a quedar más remedio que entrar en el conflicto del padre y reinvertir el orden de la exposición. El conflicto de Leonardo en torno al padre se manifiesta de la siguiente manera. Leonardo era un hombre muy dado al lujo, buena vida, buena ropa, un tipo de marcas, caballos brillantes, criados, etc, todo un look de la jet italiana que representaba bienestar y triunfo. Sin embargo, trabajaba poco y no tenía ni un duro. Simplemente a modo de curiosidad se le conoce por sus elucubraciones inventivas sobre aparatos voladores o tanques de guerra, pero Leonardo era tan fino que fue el que inventó el bocadillo y la servilleta, así como cantidad de pinchos realizados a la hoya. Tales gustos no se podían atribuir exclusivamente al deleite por la belleza sino que estaban impulsados por la obsesión de copiar y superar al padre ${ }^{3}$ (O.C.III, p. 1610). Leonardo, era hijo de una madre soltera y pobre - Catalina - a la que el padre abandonó hasta que el niño tuvo aproximadamente cuatro o cinco años, edad en la que vuelve para recuperar al hijo. Para Catalina, el padre era todo lo que una plebeya podía desear, posición social, reconocimiento, dinero, etc pero del que solo consiguió un polvo con hijo. Por su deseo pasó salir de la pobreza y entrar en a nobleza pero la realidad la frustró. El hijo sin embargo, estaba dispuesto a demostrarle al padre que él no se había caído de un guindo, quería gritarle su auténtica distinción y valía. Y ello se ve al mismo tiempo en como el genio trataba a sus obras Muchas de ellas las creaba, las alzaba a lo

\footnotetext{
${ }^{3}$ Ser Piero Da Vinci era Notario de la ciudad de Florencia y casado con la hija de un ministro de Estado. El "Ser" era indicativo de posesión de un título, de un estatus que le permite tener una profesión hereditaria dando continuidad con ello a toda una tradición familiar. Por otro lado, debemos tener en cuenta que la Florencia renacentista era como un baluarte de cultura y progreso en toda Europa, solo comparable a lo que pudo ser Paris en el S. XIX o Nueva York en el S.XX.
} 
divino pictóricamente hablando y luego las abandonaba, como su padre le abandonó a él. Fue tal la herida de esos primeros años de vida que aunque su padre la enmienda sobre los cuatro años los engramas inconscientes ya se habían adherido al genio y esa primera identificación con el padre abandónico resuena en el eco del sí mismo como una compulsión a la repetición. Como una resaca de mar que siempre se acerca a la orilla para llevarse algo y luego regresar. No obstante para Leonardo este cambio de hogar evidentemente supuso todo un ascenso en su condición social. De hecho era un hombre bastante sibarita. La ayuda de su padre además, sin duda le sirvió en positivo, de trampolín para la carrera de su hijo.

Pero hay otras figuras significativas en la infancia de Leonardo que debemos rescatar y que Freud, quizá por falta de datos no hace. Estas figuras son los abuelos por vía paterna. De ellos conocemos tan solo el nombre del abuelo Antonio. Al parecer, junto con Catalina criaron a Leonardo. De hecho la fecha de nacimiento del bebé esta registrada por el abuelo Antonio el 15 de abril de 1452, sábado, entre dos o tres horas después de media noche. En ella no figura la madre por ser ilegítima, si bien, en la fe de bautismo aparecen el nombre del párroco más diez testigos inscritos en el registro. Es decir, por la vía paterna, no se le trató jurídicamente como a un expósito. Otro dato en este sentido es que su padre al morir le deja toda la herencia a él, a pesar de haber tenido 14 hijos repartidos entre cuatro esposa, lo que supuso que los parientes interpusieran una demanda. (Field, 2007 p. 20)

\section{EL RECUERDO DE LEONARDO}

Con estos breves apuntes, y los que iremos viendo pasemos a analizar el recuerdo de Leonardo que da nombre al escrito de Freud. En los apuntes del genio solo se encuentra una breve alusión en forma de recuerdo muy temprano de su infancia de dice de la siguiente manera:

"Parece como si me hallara predestinado a ocuparme tan ampliamente del buitre, pues uno de los primeros recuerdos de mi infancia es el que hallándome en la cuna, se me acercó uno de estos animales, me abrió la boca con su cola y me golpeó con ella, repetidamente, entre los labios" (O.C.III, 1588) 
Aquí ya tenemos un problema que debemos dejar claro desde el principio. Como señala J. Strachey, Freud tomó la traducción de Herzfeld (del italiano al alemán), que estaba plagada de errores, recuérdese el aforismo latino "traductore traditione". El primero y fundamental es que en el texto original se habla de "nibio" (milano) y no de buitre y el segundo es que la cola se mete dentro de los labios.

Ante el recuerdo de Leonardo, Freud plantea tres hipótesis:

1.- Es muy difícil que un sujeto conserve recuerdos de la época de la lactancia, pero tampoco se ha demostrado científicamente lo contrario. Luego cabe una duda razonable por mínima que sea.

2.- Lo que sí es desde todos los puntos de vista cuestionable en cuanto a la realidad es que un milano se acerque a la cuna y le meta la cola en la boca del niño.

3.- La escena del buitre-o el milano en su caso -no es un recuerdo infantil, sino una fantasía adulta transferida a la infancia (Cf. 1589).

Es la hipótesis más plausible, pero resulta curioso ver como esa misma transferencia de la adultez a la infancia la podía haber empleado Freud en relación a la escena originaria contemplada por el famoso "Hombre de los lobos" (1914). El cual recordó, comprendiendo incluso el significado, que cuando tenía un año y medio contempló durante una tarde de verano el coito "a tergo" de sus padres. Si bien es cierto que ni las circunstancias políticas internas del movimiento psicoanalítico, ni las elaboraciones teóricas estaban aún enardecidas ni desarrolladas cuando se planteó el escrito de psicoanálisis aplicado de Leonardo. Por otro lado es evidente que el Hombre de los lobos es una historia clínica, de una terapia y este texto es un ensayo de psicoanálisis aplicado. No obstante esta transferencia de lo infantil a lo adulto iría más en la línea junguiana que freudiana propiamente dicha.

Dejando de a un lado estas diatribas, la cuestión que ahora se le plantea a Freud es en un principio casi un juego. Él sabe que tras los recuerdos o lo que una persona cree recordar se ocultan los auténticos testimonios de su vida anónima y en base a ello nos dice:

“...podemos emprender la tentativa de cegar la laguna existente en la historia de Leonardo por medio del análisis de su fantasía infantil. Si en esa tentativa no conseguimos llegar a una completa certidumbre, nos consolaremos pensando que 
ninguna de las investigaciones emprendidas hasta el día sobre la personalidad de Leonardo, tan elevada como enigmática ha tenido mejor fortuna" (O.C.III, 1590).

\section{INTERPRETACIÓN}

1.- La cola: no solo en italiano sino en muchos idiomas es una designación sustitutiva del miembro viril.

2.- Un ave que abre la boca de un niño, le mete la cola y la mueve repetidamente, representaría por tanto una fellation. Pero lo importante en este punto es que él es el que mama, lo hace de forma pasiva, situándose de esta manera en una fantasía homosexual de tipo pasivo donde el activo sería el ave. Retomaremos esta escena, pues no se puede quedar en esta grosería. Pero abrimos una nueva puerta, ¿era homosexual Leonardo?. Por sus biografías parece que es más que dudoso que Leonardo tuviese nunca amorosamente entre sus brazos a una mujer. Tampoco se sabe nada de amores platónicos, como por ejemplo la de Miguel Ángel por Vittoria Coloma. Sí parece que estando en el Taller de Verrocchio, su maestro, fue denunciado, en unión con otros varios jóvenes por sospechas de homosexualidad. Se le acusaba de mantener prácticas de sodomía con un joven de 17 años Jacobo Saltarelli, aprendiz de orfebre con fama de chapero. Un dato que hay que tener en cuenta es que en esa época la denuncia se podía hacer de forma anónima, pero además que la sodomía estaba penada con la muerte, si bien dicha condena nunca se llevaba a cabo. La denuncia termina no prosperando por falta de pruebas y testigos por lo que obtiene la absolución (Cf. Field, 2007).

Sobre estas acusaciones Freud nos comenta:

"No nos importa en absoluto que la denuncia...de la que fue objeto Leonardo en sus años juveniles, fuese o no justificada, pues lo que nos lleva a atribuir a una persona la inversión no es su real actividad sexual, sino su disposición sentimental" (O.C.III, 1591)

Otros datos de realidad, en torno a la presumible homosexualidad de Leonardo, era que una vez formado como pintor destacado sólo admitía como discípulos niños y adolescentes de singular belleza, con los cuales se conducía bondadosamente, asistiéndolos por sí mismo cuando enfermaban, como una madre asiste a sus hijos y 
como su madre hubo de asistirle a él. Habiéndolos escogido por su belleza y no por su talento, ninguno de sus discípulos - Cesare de Sesto, G. Boltraffio, Andrea Salaino, Francesco Melzi, etc llegó a ser de renombre (O.C.III, 1600). Pero hay algo que se percibe en el escrito de Freud, y es que él se resiste a tratar el tema de la homosexualidad de Leonardo, sin embargo su recuerdo infantil le lleva indeludiblemente a no obviarlo. En primer lugar nos dice que tras la homosexualidad no se den aceptar las teorías biológicas sin tener en cuenta la génesis psíquica y en segundo que aunque el carácter humanitario nos incline a aceptar esa igualdad biológica su práctica clínica no la ve como tal. Es decir, acepta la persona pero la ciencia no acepta la idea sin más. En esta última línea nos dice el maestro vienés:

"En todos los homosexuales sometidos al análisis se descubre un intensísismo enlace infantil, de carácter erótico y olvidado después por el individuo, a un sujeto femenino, generalmente a la madre; enlace provocado o favorecido por la excesiva ternura de la misma y apoyado después por un alejamiento del padre de la vida infantil del hijo" (O.C.III, 1598). ${ }^{4}$

Esta relación se da con especial particularidad en Leonardo, se da una relación dual, Catalina era una buena madre y una triangular fantaseada hasta la aparición del padre. Luego las cosas se complican pues Leonardo conoce otra madre sustitutiva y también buena madre. Luego en la psicodinámia de la homosexualidad la cuestión se complica pues el amor procesado hacia la madre no puede seguir con toda su fuerza de manera tan consciente (tabú del incesto) y sucumbe a la represión, pero identificándose con ella toma como modelo a su propia persona. De este modo se rebusca a sí mismo en los brazos de personas que no son mas que sustitutos de su propio yo y reproduce la escena infantil "ama como su madre le amó a él en sus primeros años" (O.C.III, 1599). Cabe aquí resaltar dos aspectos entonces, el de la identificación con la madre y el carácter autoerótico de a relación posterior. Ahora vendría otra pregunta ¿por qué si el sujeto navega tan holgadamente en las singladuras femeninas, no busca a una mujer? La respuesta es que no podría, el homosexual huye de ellas por la razón de que sería ser infiel a la omnipresente madre. De esta forma la homosexualidad se construye, no en una sola línea sino que se reconstruye constantemente a partir del atractivo de la figura

\footnotetext{
4 Nos da el ejemplo de Sadger que destaca que las madres de sus pacientes homosexuales eran generalmente mujeres hombrunas, enérgicas y que podían desplazar al padre de su puesto en la vida familiar o sustituirle. (ibid)
} 
femenina que es, en realidad lo que le dio su origen. Recordemos que Leonardo era un hombre guapo, con gusto, elegante, seductor, un dandy (datos contrastados de la biografía de Vasari, que si bien no fue contemporáneo de Leonardo pues el pintor murió cuando el biógrafo tenía ocho años, los escritos del mismo están bastante bien documentados en fuentes directas), que incluso había servido de modelo para el David de Verrocchio.

Mi experiencia clínica con homosexuales también confirma alguno de los datos que expone Freud en este escrito. Pero en la actualidad es evidente el auge creciente del mundo gay en todo lo cultural. Este altísimo porcentaje sin lugar a dudas se debe en parte al momento propicio para "salir del armario" sin tanta cortapisa social. Pero tampoco se puede reducir todo a dicha explicación. Otro aspecto lo tenemos en que el papel activo de la mujer en todos los ámbitos sociales ha desplazado al hombre como figura dominante. Hoy a Dios gracias ya no se persigue nada, puede ser más o menos popular pero nada más. Recuerdo que en mi época de estudiante decir que se era cristiano era punto menos que decir que eras franquista, estaba mal visto, era la época del porro y correr delante de la policía. Ahora da igual lo que seas, TU MISMO. Esta revolución la ha hecho la mujer, no ha sido el hombre, el hombre está a dos velas, mira pero no entiende. Y la mujer, quizá por primera vez en la historia ha cuestionado a la familia como núcleo social. Los niños reciben igualdad, pero su inconsciente busca las diferencias. En fin creo que me pierdo, perdónenme. Al mismo tiempo el homosexual tiende a liberarse, en muchas ocasiones de la cadena de esa figura materna y las heridas inflingidas por ese "amor" tan ambivalente. De hecho Leonardo en la vida más o menos adulta vivía también con rencor a la figura de su madre a la que se refería siempre como Catalina, nunca como mamá. Tampoco perdonó que sin lucha fuera entregado a su padre y se fuera a casar con otro hombre a tan solo tres kilómetros de donde el vivía. Allí Catalina continuó la prole dándole tres hermanastros. No obstante hay datos acerca de que Leonardo y Catalina volvieron a vivir juntos en torno a 1943, cuando e artista contaba entonces 41 años en Milán.

Se podría resumir la patobiografía de Leonardo, haciendo un integracionismo dinámico-cognitivo, de la siguiente manera:

Padre ausente en los primeros años de la vida, luego padre idealizado. Relación idílico-dual con la madre y con los abuelos por la vía paterna. 
Perdida de la madre a una edad vulnerable (Complejo de Edipo), en torno a los cuatro o cinco años.

Él es aceptado por la pareja de su padre, Donna Albiera, por la imposibilidad de tener hijos la pareja. Pero lo adopta con cuatro o cinco años, pues el padre se casa con Donna Albiera el mismo año que deja embarazada a Catalina. Y evidentemente no era el momento para decirle que se llevaban un hijo ilegítimo a casa.

Nacimiento de hermanastros ${ }^{5}$ y fantasías de abandono y exclusión, lo que hace que se haga un sujeto independiente y solitario.

$\mathrm{Su}$ mundo pulsional persigue compulsivamente no la salida sexual sino la sublimada de la investigación.

Su compromiso interno es tan excesivo que lo lleva a no terminar a menudo todo lo que empieza.

El arte pasa a segundo plano en su devenir sublimatorio para ser sustituido por el proceso investigador.

No obstante, Freud quiere dejar claro y yo que hoy me siento un poco su portavoz lo siguiente:

"Nada más lejos de nosotros que exagerar la importancia de estas aclaraciones de la génesis psíquica de la homosexualidad. Es indiscutible que se hallan en patente contradicción con las técnicas oficiales de los homosexuales, pero sabemos que no son lo suficientemente amplias para facilitar una definitiva aclaración del problema. Aquello que por razones prácticas denominamos homosexualidad puede surgir de muy diversos procesos psicosexuales de coerción, y el proceso por nosotros descubierto no es quizá sino uno entre muchos, no refiriéndose sino a uno de los diversos tipos de homosexualidad" (O.C.III, 1598)

Recuérdese que Freud en los Tres ensayos para una teoría sexual 1905, diferenciaba entre homosexualidad ocasional, anfígena y permanente.

\footnotetext{
${ }^{5}$ Por parte de madre tiene tres, pero por parte de padre son catorce los hermanos que alcanza a raíz de cuatro matrimonios.
} 
Pero retomemos la fantasía de Leonardo, en ella nos encontramos indicios de homosexualidad pasiva, pero a lo que en última instancia nos lleva el recuerdo es al acto de mamar el pecho materno, el de ser besado por la madre, al sublime momento de la lactancia. Porque el auténtico placer de una mamada, tanto del homosexual como en el caso de la enamorada, no es otro que la rememoración de aquella época dorada en la que nos sentíamos felices enganchados al pezón de la madre. Y que Freud asocia tanto a nivel psicológico como fisiológico. Es decir, sería la asociación orgánica de placer físico y la sensación de placer psíquico lo que haría que el acto de mamar se convirtiera en inefable. Luego en Leonardo, tras el recuerdo infantil tendríamos una fantasía homosexual transformada del primigenio recuerdo de ser amamantado por la madre. Posteriormente, Freud encaja su puzzle casi perfecto en relación al símbolo del buitre y lo materno, la fecundidad, etc, basado en la mitología egipcia. Vale la pena leerlo pues nos da la evidencia de su ingenio y de su sólida formación clásica. Si bien, partió de un error en las fuentes, que ya hemos mencionado, el de milano por buitre. Por ello sus conclusiones a la par que dignas son también muy literarias.

Un dato del que es interesante y que nos da igual si es milano, buitre o lechuza, en el recuerdo es que Leornardo sustituye a la madre por un ave. Lo que de alguna manera sitúa al mismo como un polluelo. Hammer, 1992; de Santiago et al 1999 concluyen que el ave en los test gráficos puede representar dos cuestiones: o bien la libertad, o su opuesto el control superyoico ejercido por una figura de autoridad. En ausencia de datos Freud solos e atreve a afirmar que Leonardo se sintió abandonado y solitario al lado de su madre en esta primera etapa de su vida (cf. 1593). Y con ello, nos introduce, sin nombrarlo, en el concepto de núcleo de la personalidad. Nos dice al respecto:

"En los tres o cuatro primeros años de vida quedan fijadas ciertas impresiones y establecidas ciertas formas de reacción entre el mundo exterior que no pueden ser despojadas ya de su importancia y sentido por ningún suceso ulterior” (O.C.III, 1594)

Es decir, sobre esta base, se va creando la urdimbre, el conjunto de hilos para formar la tela. Urdimbre que Rof Carballo denominó afectiva (1987). 
Freud en base a la fantasía plantea la siguiente hipótesis:

"La bondadosa naturaleza ha dado al artista la facultad de exteriorizar por medio de creaciones, sus más secretos sentimientos anímicos, ignorados inclusos por él mismo, y esta exteriorización nos conmueve profundamente, sin que sepamos de donde proviene tal emoción. En la obra de Leonardo habrá de existir por tanto, algún testimonio de aquello que su memoria ha conservado como la impresión más poderosa de su infancia" (O.C.III, 1603)

En la primera parte nos da claves acerca de las cualidades del artista y del arte, como el ser un don natural, donde el inconsciente juega un papel importante en el proceso creativo y un detalle importante y es que en arte no todo vale, es decir, una obra de arte tiene que trasmitir de alguna manera algún tipo de conflicto sobre el que nos podamos identificar y sentir algo en su contemplación o en su escucha, si no carece de sentido.

El problema de la segunda y parte central de la hipótesis, es la falta de datos autobiográficos de Leonardo y resulta por tanto muy dificultoso fijar con ciertos márgenes de seguridad esas transformaciones tan profundas de su vida infantil y su producción pictórica o artística.

Freud se va a centrar primero en Monna Lisa de Giocondo ${ }^{6}$. Se trata de una obra tardía de Leonardo, en torno a 1513 y que se trata muy probablemente de la esposa del Marqués Francesco del Giocondo. La técnica pictórica es un intenso sfumato donde figura y paisaje quedan fundidos en una especie de cuadro cósmico donde se aúna la introspección y el panteísmo.

Resulta curioso, como en su Tratado de Pintura (2005) en la L. "De los varios movimientos y operaciones" nos sugiera el egregio pintor lo siguiente:

"Las figuras deben representarse con aquella actitud propia únicamente de la operación en que se fingen; de modo que al verlas se conozca inmediatamente lo que quieren decir" (p. 75-76).

\footnotetext{
${ }^{6}$ Óleo sobre tabla de 77x53 cm en el Museo de Louvre de Paris.
} 
Y, sin embargo nos encontramos con esta sonrisa "Leonardesca" que tantos ríos de tinta ha suscitado. Realmente nadie más que Leonardo sabe que se encuentra tras la mirada y sonrisa de la Monna Lisa. Sabemos que tardó años en pintarla, qué se dedicó casi exclusivamente a ella pero que aun siendo un encargo nunca lo entregó, bajo la excusa de no sentirse satisfecho con la obra se la llevó consigo a Francia. Y digo bajo la excusa porque esa cara le había fascinado sobremanera, estaba obsesionado como Pigmalíón enamorado de su propia obra. Y todo ello más allá de que él mismo aconsejara que se tuviera cuidado en no repetir rostros, pues no existen facciones iguales entre los hombres.

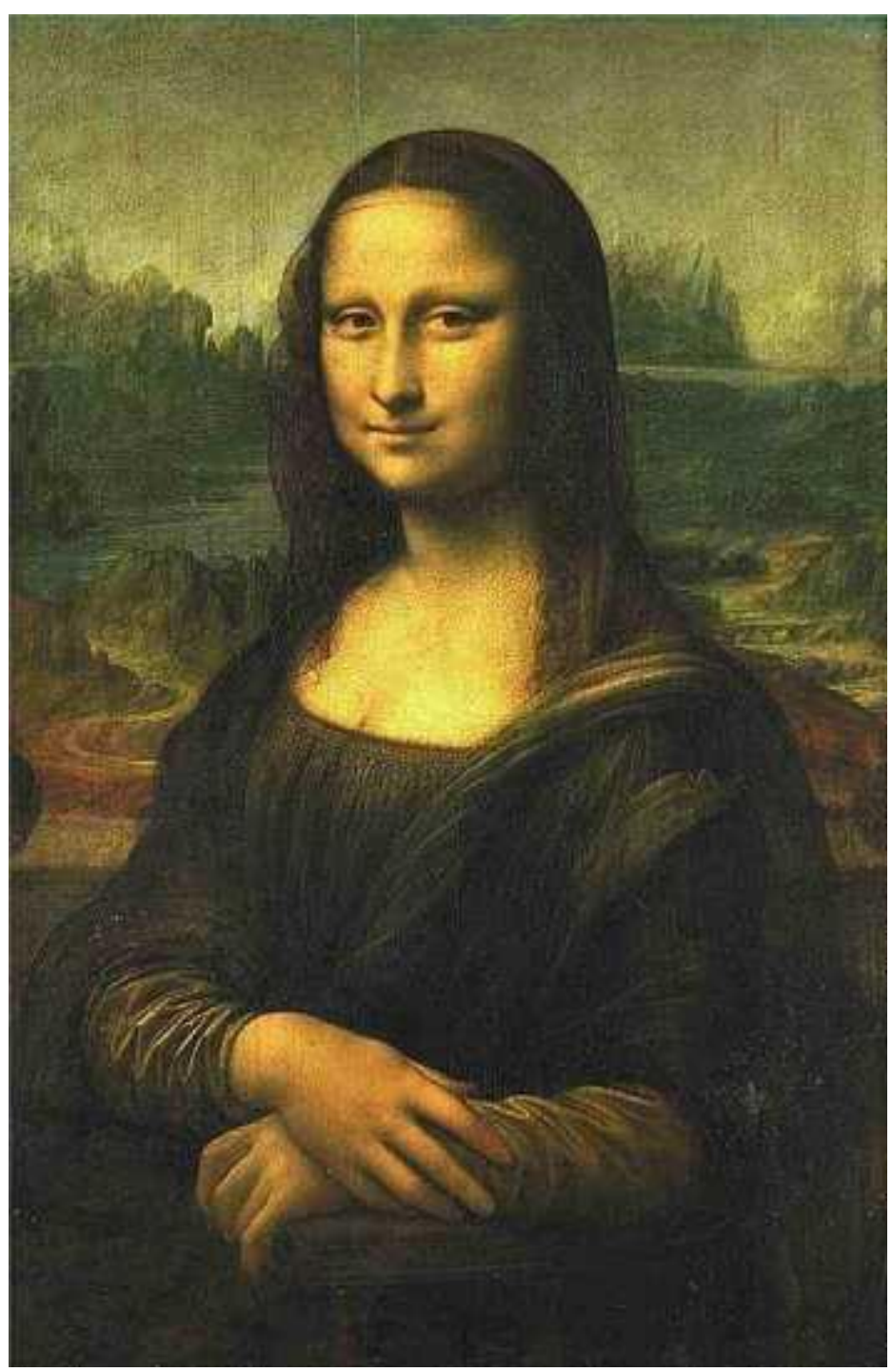


Sin embargo vemos como transfiere la mirada y la sonrisa de la Gioconda en la imagen del andrógino San Juan Bautista ${ }^{7}$ de 1513 y en el anterior de 1507 Santa Ana, La Virgen y el Niño ${ }^{8}$

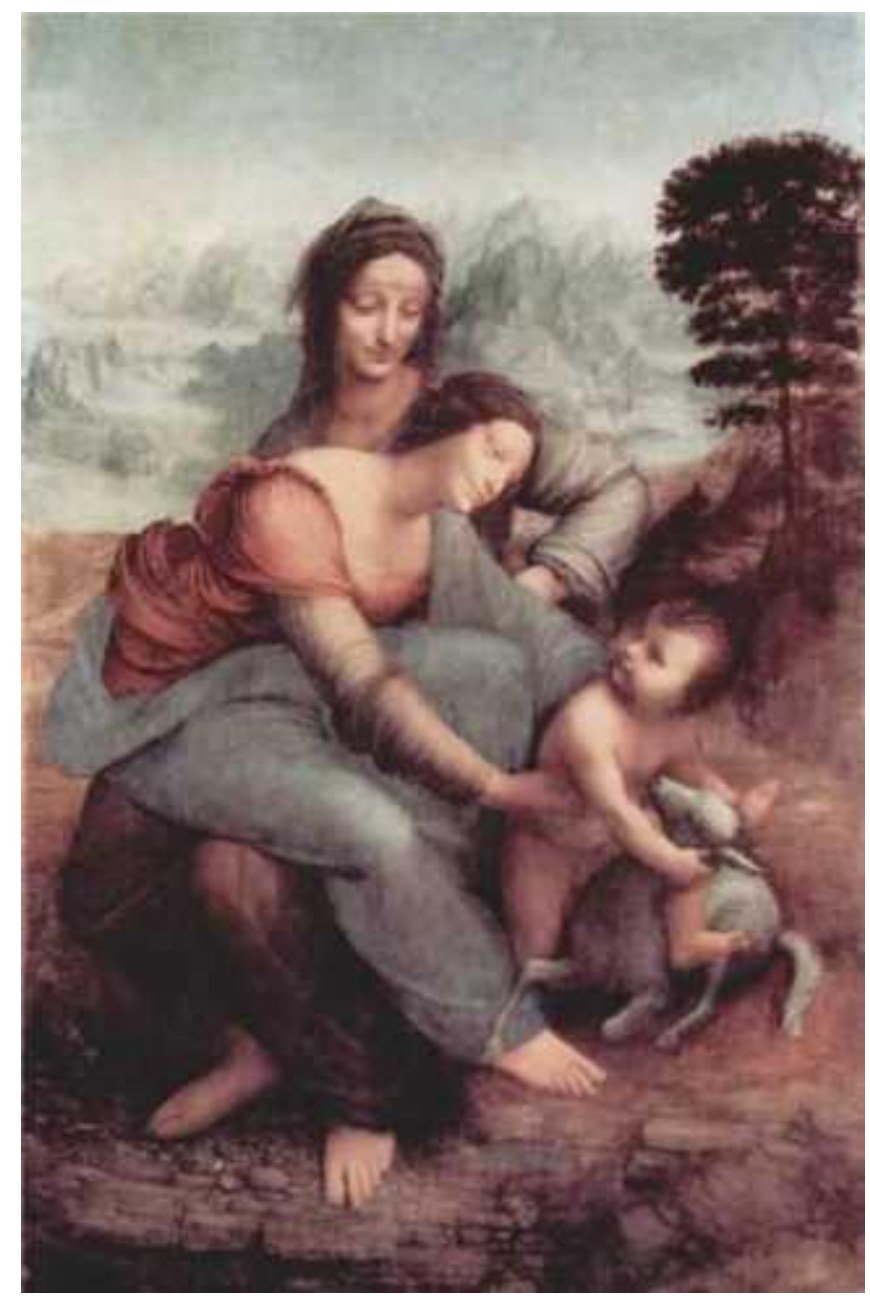

\footnotetext{
${ }^{7}$ Oleo sobre tabla de 69x57 cm en el Museo de Louvre Paris.
}

${ }^{8}$ Sobre tabla 168x130cm Museo de Louvre Paris 
La hipótesis freudiana:

Herzlfeld, citado por Freud (O.C.III, 1605) opina que Leonardo se encontró a sí mismo en Monna Lisa, por ello le fue tan difícil concluirla y mucho mas despojarse de ella, pero se encontró con rasgos de sí mismo que se albergaban desde hacia mucho tiempo en su más tierna infancia. Vasari alude a que sus primeros ensayos artísticos los realiza sobre las cabezas de los niños. Dice Leonardo LXI: Los niños deben dibujar con actitudes prontas y vivas, pero descuidadas cuando están sentadas; y cuando están de pie se deben representar con alguna timidez en la acción" p. 79. Si asociamos que las cabezas y los niños esa producto de la repetición de su propia infancia, es decir, de él mismo, las mujeres sonrientes no podían ser otras que Catalina, su madre y de aquí que surja la sospecha de que su madre biológica poseyera de alguna manera esa enigmática sonrisa. Sonrisa que desapareció para Leonardo en torno a los cuatro o cinco años y que reencontró cerca de los 50 en los labios de la dama florentina. Luego la conclusión primera es que tras la sonrisa leonardesca se escondía la sonrisa de la madre. El reencuentro con la sonrisa perdida actúa de impulso dinámico en Leonardo para dignificar y glorificar el retorno y acto seguido el cuadro más inmediato que realiza es el de la Virgen Santa Ana y el Niño. Donde ambas mujeres comparten la misma sonrisa. 
En primer lugar, era muy poco corriente en la pintura italiana pintar a Santa Ana, la Virgen y al Niño juntos. Lo normal, era la Virgen y el Niño, con San José y quizá algún cuadro con San Juan Bautista, pero no a la abuela.

En segundo lugar, la abuela no se diferencia en cuanto a la edad de la Virgen. Müther, citado por Freud, alude que Leonardo detestaba pintar la ancianidad, sin embargo no es cierto. En su Tratado de pintura en la LXIII, nos indica como pintar ancianos y por si fuera poco él mismo se pinta de anciano retratado como Platón. Luego Da Vinci tenía un canon y un estilo establecido para tal edad. Es decir, no pinta a una mujer madura y diferenciada en años de la Virgen simplemente porque no quiere. Y la cuestión radica en ese por qué no quiere dar a cada una sus estados -abuela-madre-. Es muy posible que tras ello esté que precisamente Leonardo tuvo dos madres. Catalina, la madre biológica, de cuyos brazos fue arrebatado con cuatro años y Donna Albiera, la mujer de su rico padre.

Catalina, hace el papel de la abuela, la más primitiva, la pobre que ríe. para ocultar el dolor y la envidia, mientras que Donna Albiera juega el papel de la Virgen la victoriosa rica que posee al hijo y sonríe de felicidad en primer plano.

Posteriormente Leonardo retoma la sonrisa, pero ya no la mirada. Lo hace en un adolescente andrógino que mira de forma triunfal como escondiendo un secreto. Parece que va a salir del armario y darnos a todos un corte de manga. El niño perturbado por la ternura materna reúne las características masculinas y femeninas ocultando su fracaso en su vida erótica.

Con todo ello Freud quiere dejar claro que no ha contado nunca con Leonardo entendiéndolo como un neurótico o como un enfermo mental especial. De hecho nadie duda de la personalidad genial del mismo. Pero también deja un aspecto cualitativo importante y es que:

"No creemos ya que la salud y la enfermedad, lo normal y lo nervioso, puedan ser precisamente diferenciados ni que los caracteres neuróticos deban ser considerados como prueba de inferioridad" (O.C.III,1615)

Freud nos viene a decir que la diferencia en el pathos más que una cuestión cualitativa se debe a una cuestión cuantitativa, y que en última instancia nadie está libre 
de conflictos neuróticos. En el estudio que hace Freud lo único que se pretende es vislumbrar los alcances de la vida inconsciente, para comprender como esta fuente moviliza y determina nuestras vidas. No se oscurece para nada la brillante luz del genial artista y científico, sino por el contrario, la comprensión de su humana dimensión nos acerca al hombre, sujeto a las mismas leyes que rigen en todos tanto la actividad normal, como la patológica (González Rojas, González Lobeto, 2004)

En fin para concluir, me gustaría también cerrar la conferencia con una pequeña frase del maestro vienés acerca del famoso caso de psicoanálisis aplicado sobre el presidente Schreber.

El porvenir decidirá si la teoría integra más delirio del que yo quisiera o el delirio más verdad del que otros creen que hoy es posible (S. Freud O.C.II. p. 1526) 


\section{BIBLIOGRAFÍA}

Alonso Fernández, F (1984) Psicopatología y creatividad UPSA, Salamanca.

Carballo, R. (1987) Violencia y ternura Espasa Calpe, Madrid

Da Vinci, L. (2005) Tratado de pintura Edimat, Madrid

Field, D.M. (2007) Leonardo Da Vinci Spain Lisma.

Freud, S 1904 Personajes psicopáticos en el teatro

Freud, S 1908 El poeta y la fantasía.

Freud, S. 1905 Tres ensayos para una teoría sexual

Freud, S. 1910 Un recuerdo infantil de Leonardo Da Vinci

Freud, S. 1912-1913 Tótem y Tabú

Freud, S. 1913 [1914] El Moisés de Miguel Ángel

Freud, S. 1914 Múltiple interés del psicoanálisis

Freud, S. 1914 Historia de una neurosis infantil (Caso del "Hombre de los lobos")

Gómez Sánchez, C (2002) Freud y su obra. Génesis y construcción de la teoría psicoanalítica Biblioteca Nueva APM, Madrid

González Rojas, T y González Lobeto, J.E. (2004) Una aproximación psicodinámica al genio creador de Leonardo Da Vinci. En Revista de Ciencias de la Educación Año 4 Vol 1 nº 23 Valencia Enero-Junio pp. 161179

Monedero Gil, C. (1985) Psicoanálisis y creatividad UPSA, Salamanca

Ramos, M.A. (2005) Estudio Preliminar. Leonardo Da Vinci. Tratado de Pintura. En Leonardo Da Vinci Tratado de Pintura Edimat, Madrid

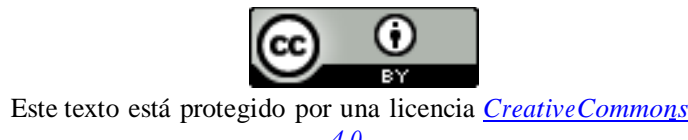

4.0.

Usted es libre para Compartir — copiar y redistribuir el material en cualquier medio o formato - y Adaptar el documen- to -remezclar, transformar y crear a partir del material- para cualquier propósito, incluso comercialmente, siempre que cumpla la condición de:

Atribución: Usted debe reconocer el crédito de una obra de manera adecuada, proporcionar un enlace a la licencia, e in- dicar si se han realizado cambios. Puede hacerlo en cualquier forma razonable, pero no de forma tal que sugiera que tie- ne el apoyo del licenciante o lo recibe por el uso que hace. 